IZA DP No. 4707

Profit Sharing, Wage Formation and Flexible Outsourcing under Labor Market Imperfection

Erkki Koskela

Jan König

January 2010 


\title{
Profit Sharing, Wage Formation and Flexible Outsourcing under Labor Market Imperfection
}

\author{
Erkki Koskela \\ University of Helsinki \\ and IZA \\ Jan König \\ Free University Berlin
}

\section{Discussion Paper No. 4707 \\ January 2010}

\author{
IZA \\ P.O. Box 7240 \\ 53072 Bonn \\ Germany \\ Phone: +49-228-3894-0 \\ Fax: +49-228-3894-180 \\ E-mail: iza@iza.org
}

Any opinions expressed here are those of the author(s) and not those of IZA. Research published in this series may include views on policy, but the institute itself takes no institutional policy positions.

The Institute for the Study of Labor (IZA) in Bonn is a local and virtual international research center and a place of communication between science, politics and business. IZA is an independent nonprofit organization supported by Deutsche Post Foundation. The center is associated with the University of Bonn and offers a stimulating research environment through its international network, workshops and conferences, data service, project support, research visits and doctoral program. IZA engages in (i) original and internationally competitive research in all fields of labor economics, (ii) development of policy concepts, and (iii) dissemination of research results and concepts to the interested public.

IZA Discussion Papers often represent preliminary work and are circulated to encourage discussion. Citation of such a paper should account for its provisional character. A revised version may be available directly from the author. 


\section{ABSTRACT \\ Profit Sharing, Wage Formation and Flexible Outsourcing under Labor Market Imperfection*}

We combine profit sharing and outsourcing, if the wage for worker is decided by a labor union to analyze how does the implementation of profit sharing affect individual effort and the bargained wage and thus outsourcing? We find that profit sharing and the wage level have an individual effort-augmenting effect and therefore increase productivity. We also find that the wage effect of profit sharing is ambiguous. There is a wage decreasing substitution effect, but on the other hand, there is a wage increasing effect via labor demand elasticity so that outsourcing and employment effects are also ambiguous.

JEL Classification: E23, E24, J23, J33, J82

Keywords: flexible outsourcing, profit sharing, employee effort, labor market imperfection

Corresponding author:

Erkki Koskela

Department of Economics

University of Helsinki

P.O. Box 17 (Arkadiankatu 17)

00014 Helsinki

Finland

E-mail: erkki.koskela@helsinki.fi

\footnotetext{
* The authors acknowledge financial support from the Research Unit of Economic Structures and Growth (RUESG), financed by Academy of Finland, University of Helsinki, Yrjö Jahnsson Foundation, Bank of Finland and Nokia Group. Koskela also thanks the Academy of Finland (grant No. 1217622) for further financial support and Freie Universität Berlin for good hospitality. König thanks University of Helsinki for good hospitality.
} 


\section{Introduction}

It is often argued that high wage or labor costs in Western Europe are the driving force behind the increasing business practice of international outsourcing across industries (see e.g. Stefanova (2006) and Amiti and Wei, (2005)). One reason for the wage gap to Eastern Europe or Asian countries is the difference in labor market institutions. Typically in Western Europe, wages for low-skilled workers are set by the government via minimum wage arrangements or determined by bilateral bargaining between firms or employer federations and labor unions. In opposite, unions in Eastern European or Asian countries are much weaker or wages are determined by market forces. Therefore, flexible outsourcing, which is decided after knowing the domestic production costs, is a significant threat for employment in the low-skilled segment in industrialized countries. To working against this threat and making domestic production more attractive, lower wages or higher productivity are needed. This can be realized by the introducing a profit sharing scheme, which is often expressed by labor unions or politics. Due to this scheme the relationship of income and wage will be released. Thus, the same income can be derived with a lower wage.

Although profit sharing is an important phenomenon in OECD countries ${ }^{1}$, the productivity effect of such a participation in firm's success is ambiguous. ${ }^{2}$ It is argued, that due to profit sharing motivation and identification with the firm is stimulated and thus effort respectively productivity increases. On the other hand, if workers share in the firm's profit, the incentive of manager to shirk the monitoring function increases, which decreases the productivity. Additionally, there could be free riding behaviour, since if there are $n$ employees and profits will be equally distributed, so that an individual receives only $1 / n$ of the extra profits, which lead to fewer incentives to increase effort.

However, profit sharing will also affect the wage bargaining. Concerning the wage effect of profit sharing several studies confirm that higher profit sharing

Pendleton et al. (2001) have presented detailed data on profit sharing schemes in 14 OECD countries. For further evidence regarding the incidence of profit sharing, see also Estrin et al. (1997) and Conyon and Freeman (2004).

For an increasing effect on productivity see Cable and Fitzroy (1980), while, Jensen and Meckling (1979), and Kruse (1993) demonstrate negative productivity effects of profit sharing. 
will decrease the bargained wage by labor unions. ${ }^{3}$ This results since higher wages decrease the profit of a firm and thus decrease the profit income of the worker or union member. Due to this loss, the union's marginal costs of an increasing wage are higher and therefore, higher profit sharing will induce a less aggressive wage setting.

Bringing the finding concerning the relationship between domestic wage level and outsourcing activities plus the wage decreasing effect of profit sharing together, one would expect that profit sharing will lower outsourcing demand. However, as it is shown in Koskela and König (2009), profit sharing could decrease the bargained wage and therefore outsourcing activities, but if the labor union sets also the effort or productivity level, the firm will desist from implementing a profit sharing scheme. Thus, there is no effect of profit sharing on outsourcing demand.

In contrast to Koskela and König (2009), in this paper we combine profit sharing and outsourcing, if the wage for worker is decided by a labor union but effort is decided by the worker. In this context, we analyze the impacts of profit sharing on firm's incentive to outsource domestic production by answering the following three questions: First, how does the implementation of profit sharing affect effort and thus productivity? Second, how does profit sharing influence the bargained wage and thus outsourcing demand? Third, will the firm implement a profit sharing scheme, if workers decide individually about effort provision?

We find that profit sharing and the wage level have an individual effortaugmenting effect and therefore increase productivity. This results from the fact, that higher profit sharing increases the income, which sets incentive to increase the profit due to higher effort. Concerning our second question, we demonstrate that the wage effect of profit sharing is ambiguous. On the one hand, there is a wage decreasing substitution effect, but on the other hand, there is a wage increasing effect via labor demand elasticity. Therefore, the outsourcing or employment effect is also ambiguous. To our third question, we find that there will be a profit sharing scheme, which characterize a difference to Koskela and König (2009).

See e.g. Weitzman (1987), Wadhwani (1988), Fung (1989), Holmlund (1990) and Koskela and Stenbacka (2006). However, there are also empirical studies, such as Wadhwani and Wall (1990) and Kraft and Ugarkovic (2005), which show that profit sharing does not reduce the wage. 
We proceed as follows. Section II presents the time sequences of decisions. Also, the labor and outsourcing demand and employee effort are presented. Section III investigates the wage formation by monopoly labor union and the optimal profit share. Finally, we present conclusions in section IV.

\section{The Basic Framework and Optimal Flexible Outsourcing, Labor Demand and Individual Employee Effort}

We assume that output depends not only on domestic labor and international outsourcing, but also on the effort by workers, i.e. the workers' productivity. This lies in conformity with the efficiency wage hypothesis. ${ }^{4}$ We analyze the following timing decision, which captures the idea that the representative firm is flexible to decide about the amount of outsourcing simultaneously with domestic labor demand, but commits to profit sharing before wage determination. After the firm has decided about profit sharing, the monopoly labor union sets the wage given the profit share level. Knowing the base wage the representative firm determines outsourcing and employment. If the wage and profit share level is known, the representative worker decides on effort provision. We summarize these timing decisions in Figure 1. The decisions at each stage are analyzed by using backward induction.

Figure 1: Time sequences of decisions in terms of outsourcing, employment, effort, wage formation and profit sharing

Flexible outsourcing and committed profit sharing:

Stage $1 \quad$ Stage $2 \quad$ Stage 3

profit wage outsourcing $M$, labor demand $L$ sharing $\tau \quad$ formation $w \quad$ and effort determination $e_{i}$

See e.g. the book edited by Akerlof and Yellen (1986), which includes the main initial efficiency wage papers about (i) shirking models, (ii) labor turnover models, (iii) adverse selection models and (iv) sociological models. 
First we characterize the optimal labor and outsourcing demand by the representative firm and the effort by the representative worker by taking profit sharing and wage formation as given. The concave production function with respect to effective labor and outsourcing is presented

$$
F(\bar{e} L, M)=\frac{1}{\alpha}(\bar{e} L+M)^{\alpha} \text {, with } 0<\alpha<1
$$

where the price of the output is normalized to unity, $L$ is the amount of domestic labor and $M$ the firm's labor input acquired from external suppliers through outsourcing. The parameter $\bar{e}$ describes the total average effort of the firm's

worker, where the average effort is defined as $\bar{e}=\frac{1}{L} \sum_{i=1}^{L} e_{i}$, so that the impact of provision of an additional unit of effort by a single worker is $\frac{\partial \bar{e}}{\partial e_{i}}=\frac{1}{L} \cdot{ }^{5}$ As one can see from (1), we assume that domestic effective labor, $\bar{e} L$, and outsourcing, $M$, are perfect substitutes.

\section{II.1. Outsourcing and Domestic Labor Demand}

The firm decides on domestic labor and outsourcing to maximize the profit function

$$
\underbrace{\operatorname{Max}}_{L, M} \pi=\frac{1}{\alpha}(\bar{e} L+M)^{\alpha}-w L-f(M) .
$$

by taking the average effort, $\bar{e}$, wage, $w$, and profit sharing, $\tau$, as given. For the cost of outsourcing, we assume there are some other costs associated with outsourcing such as the price of the intermediate goods. Such costs could be costs for transport, which are exponential increasing with higher outsourcing. To allow

A specification, which is also common in the literature, describes effort as the fraction of working hours that the worker actually works. Since the number of working hours is normalized to 1 , the choice of an individual is $e_{i} \in(0 ; 1)$ and thus $\left(1-e_{i}\right)$ characterizes the fraction of time spent shirking. Following this $\bar{e} L$ is the whole actual working time. 
for an exponential cost increase, we model a quadratic cost function, $f(M)=\frac{1}{2} c M^{2}$ with $f^{\prime}(M)>0$ and $f^{\prime \prime}(M)>0$.

The first-order conditions of (2) are $\pi_{L}=\bar{e} \cdot(\bar{e} L+M)^{\alpha-1}-w=0$ and $\pi_{M}=(\bar{e} L+M)^{\alpha-1}-c M=0$, which can be expressed as

$$
\begin{aligned}
& L=w^{-\frac{1}{1-\alpha}} \bar{e}^{\frac{\alpha}{1-\alpha}}-\frac{M}{\bar{e}}=w^{-\frac{1}{1-\alpha}} \bar{e}^{\frac{\alpha}{1-\alpha}}-\frac{w}{c \bar{e}^{-2}}, \\
& M=\frac{w}{c \bar{e}} .
\end{aligned}
$$

In the case of perfect substitutability domestic labor demand is a negative function of wage and the amount of outsourcing and a positive function of both outsourcing cost and effort. Higher outsourcing will decrease domestic labor demand, which lies in conformity with empirics. ${ }^{6}$ However, labor demand does not directly depend on profit sharing, which lies also in conformity with empirical evidence. ${ }^{7}$

At this stage, we can also look on the direct labor demand elasticities. In the presence of outsourcing the direct own wage elasticity of the labor, $\eta_{w}=-\frac{\partial L}{\partial w} \frac{w}{L}$, and the effort elasticity of the labor, $\eta_{\bar{e}}=\frac{\partial L}{\partial \bar{e}} \frac{\bar{e}}{L}$, can be written as

$$
\begin{aligned}
& \eta_{w}=\frac{1}{1-\alpha}\left(1+\frac{M}{\bar{e} L}\right)>1, \\
& \eta_{\bar{e}}=\frac{\alpha}{1-\alpha}+\frac{1}{1-\alpha} \frac{M}{\bar{e} L}=\eta_{w}-1>0 .
\end{aligned}
$$

\section{II.2. Individual Employee Effort}

By following the efficiency wage literature we assume for the employed worker that the utility function is additively separable in income and effort, where the utility depends positively on the wage and profit income and negatively on the disutility of effort. The employed worker receives an income of $y$, which includes

See e.g. Görg and Hanley (2005).

See e.g. Wadwani and Wall (1990) and Cahuc and Dormont (1997). 
both the wage $w$ and the profit income $\tau \frac{\pi}{L}$ so that the overall remuneration is $y=w+\tau \frac{\pi}{L}$. The idea behind this is that the workers are assumed a team. The whole team gets the profit share $\tau \cdot \pi$, what is distributed equally to the member. However, to get the profit income, it causes effort provision of a worker. Since worker dislikes effort provision, it is associated with a disutility, which can be describe by $g(e)$, where $g(e)=\gamma \cdot e^{1 / \gamma}$ is assumed to be a convex function with $0<\gamma<1$ so that $g^{\prime}(e)=e^{(1 / \gamma)-1}>0$ and $g^{\prime \prime}(e)=[(1 / \gamma)-1] e^{(1 / \gamma)-2}>0$.

Since the profit is equally distributed, every (homogenous) worker gets the same per capita profit income, but he/she realizes the individual disutility for providing a certain effort level. Thus there is space for a free-rider behavior by the single worker, which means that there is an incentive for shirking. The biggest problem of firm's owner is to solve this moral hazard problem and to verify the individual effort. However, in the discussion of the free-rider problem interaction of the group member and peer pressure are often neglected. Due to the implementation of profit sharing there are incentives in the group to internalize the externalities of free-riding and avoiding shirking, since it sets some incentive to observe each other and interact. ${ }^{8}$ This can build up a peer pressure to provide the individual effort resulting from individual utility maximization and eliminate the moral hazard problem concerning the free-rider behavior. Following Kandel and Lazear (1992), we motivate this peer pressure as a social group norm. Due to the observation, the individual fells shame or guilty if the individual effort is below this norm, since it lowers the income for each of the team member. However, also an effort above the norm will decrease the individual utility, since now the other team member will feel shame. Thus any deviation from the norm will lead to a utility loss. Therefore, the peer pressure function can be written simply as $P\left(e_{i}\right)=\left(\tilde{e}-e_{i}\right)^{2}$, where $\tilde{e}$ is the social norm and defined as the average effort of all other worker than $i .^{9}$

$8 \quad$ See Holmstrom (1982), Holmstrom and Milgrom (1990) and Varian (1990). Radner (1986) shows, that in repeated games the free-rider problem can be eliminated even if the players cannot observe other players' actions or information, but can observe the consequences.

$9 \quad$ We assume that every group member can verify the effort of the others, but the firm owner cannot do this. The punishment of the shirking or over motivated members is a utility loss and not an income loss, and can be interpreted as mental harassment or social exclusion. 
From this framework we can write the utility of a single employed individual in (5a) and of an unemployed individual in (5b)

$$
\begin{aligned}
& v=w+\tau \frac{\pi}{L}-\gamma e_{i}^{1 / \gamma}-\left(\tilde{e}-e_{i}\right)^{2}, \\
& \bar{v}=b .
\end{aligned}
$$

The worker's problem is to choose the level of individual effort to maximize its utility. For simplicity of analysis, suppose that observation of team member is costless and that the group norm is not affected by the individual effort. In what follows $\frac{\partial \tilde{e}}{\partial e_{i}}=0 .{ }^{10}$ Thus the optimal individual provided effort level results from individual utility maximization of (5a) with respect to effort, which yields the firstorder condition ${ }^{11}$

$$
v_{e}=\frac{\tau}{L} \pi_{e}-e^{(1 / \gamma)-1}+2(\tilde{e}-e)
$$

Since we focus on individual effort determination, the effect on employment will be not taken into account. Therefore, $\pi_{e}=F_{e}$ holds and using the production function (1) and $\bar{e}=\frac{1}{L} \sum_{i=1}^{H} e_{i}$, which leads to $\frac{\partial \bar{e}}{\partial e_{i}}=\frac{1}{L}$, we obtain $F_{e}=F_{\bar{e}} \cdot \bar{e}_{e}=(\bar{e} L+M)^{\alpha-1}$. Inserting the labor and outsourcing demand, equations (3a) and (3b), we find for the individual effect on profit $\pi_{e}=F_{e}=w / \bar{e}$. Since we also assume Nash-behaviour, where every worker takes the effort of the others as given, the individual chooses an effort level equal to the group norm. However, every group member faces the same calculus, which means that the group norm corresponds to the average effort level. Assuming homogenous workers, the average effort level equals individual effort and thus effort level which would be chosen without any peer pressure. Finally, we have $e=\tilde{e}=\bar{e}$. Using this, we get from solving equation (6) the effort function

10 In our framework we assume Nash behavior, where every worker chooses his/her effort taking the effort of others as given. So there is no effect of effort provision by the other workers and thus no effect on the social norm. See also Lin et al. (2002). The index $i$ has been dropped for notational convenience. 


$$
e=\bar{e}=\left(\frac{\tau \cdot w}{L}\right)^{\gamma}
$$

Therefore, the optimal effort by the representative worker is influenced by the income parts, but outsourcing will have no direct effect.

Since changes in wage and profit income affect all workers, every single worker will adjust its effort and thus the average effort will change. These effects we derive by taking the differential of effort function (7), which give $\frac{d \bar{e}}{d w}=\frac{\gamma\left(1+\eta_{w}\right)}{1+\gamma\left(\eta_{w}-1\right)} \frac{\bar{e}}{w}>0$ and $\frac{d \bar{e}}{d \tau}=\frac{\gamma}{1+\gamma\left(\eta_{w}-1\right)} \frac{\bar{e}}{\tau}>0$, so that the wage and profit sharing enhance productivity by increasing effort provision and positively affect labor demand indirectly, which lies in conformity with empirics. ${ }^{12}$

Important for the next analysis is the wage elasticity of effort. In our framework we find as

$$
\phi=\frac{d \bar{e}}{d w} \frac{w}{\bar{e}}=\frac{\gamma+\gamma \eta_{w}}{1-\gamma+\gamma \eta_{w}}\left\{\begin{array}{l}
< \\
= \\
>
\end{array}\right\} \text { as } \gamma\left\{\begin{array}{l}
< \\
= \\
>
\end{array}\right\} \frac{1}{2}
$$

so that the elasticity of effort in terms of wage is only one if we have the specific parameter $\gamma=1 / 2$ for the disutility of effort. ${ }^{13}$ According to (8) the effort elasticity increases (decreases) if the disutility of effort becomes less (more) convex. Since we are interested in the effect of profit sharing if the wage is determined by a labor union, we have to assume $\gamma<1 / 2$. The reason for that assumption is that only in this case the low skilled wage setting by the labor union would be binding.

For the effort elasticity concerning profit sharing we found that it is positive, but smaller than one, i.e. $\mu=\frac{d \bar{e}}{d \tau} \frac{\tau}{\bar{e}}=\frac{\gamma}{1+\gamma\left(\eta_{w}-1\right)}>0$.

We can now summarize our findings as.

12 See e.g. Booth and Frank (1999), Cable and Wilson (1990), Cahuc and Dormont (1997), Kruse (1992), Lynn Hannan (2005) and Wadhwani and Wall (1990).

13 In a dynamic efficiency wage model in the absence of outsourcing Jellal and Zenou (2000) have received the same result in terms of effort wage elasticity. 
Proposition 1: Profit income and base wage have an individual effortaugmenting effect and thus increase productivity, whereas the wage elasticity of effort depends on the parameter of disutility of effort so that it can be smaller, equal to, or higher than one.

For the above mentioned reason, in the following analysis, we concentrate on the case when the wage elasticity of effort is smaller than one, i.e. $\phi<1$.

\section{Wage Formation by Monopoly Labor Union and Committed Profit Sharing}

Now we analyze the stage when the representative firm commits to profit sharing before the wage formation by allowing for their effects on wage setting, labor demand and effort determination.

\section{III.1. Wage Formation under Committed Profit Sharing}

We first analyze the wage formation by the monopoly union (see also Cahuc and Zylberberg (2004), p. 401-403) by taking profit sharing as given and by assuming that the union behaves utilitaristic in the presence of effort determination. Therefore the objective function of monopoly labor union is assumed to be $V=v L+(N-L) \bar{v}$, which we can rewrite by using equations (5a) and (5b) to maximize the surplus anticipating domestic labor demand, outsourcing and effort determination according to

$$
\begin{aligned}
\underbrace{\operatorname{Max}}_{w} V & =(w-g(\bar{e})-b) L+\tau \pi+b N, \text { s.t. } \\
L & =w^{-\frac{1}{1-\alpha}} \frac{\alpha}{\bar{e}^{1-\alpha}}-\frac{M}{\bar{e}}=w^{-\frac{1}{1-\alpha}} \frac{\alpha}{\bar{e}^{1-\alpha}}-\frac{w}{c \bar{e}^{-2}} \\
e & =\bar{e}=\left(\frac{\tau \cdot w}{L}\right)^{\gamma}
\end{aligned}
$$

where $b$ captures the exogenous minimum income for labor union members $N$.

We get following as the first order condition 


$$
V_{w}=\frac{L}{w}\left[\frac{d L}{d w} \frac{w}{L}(w-b-g(\bar{e}))+\tau \frac{d \pi}{d w} \frac{w}{L}+w\left(1-\frac{d g(\bar{e})}{d w}\right)\right]=0,
$$

where the overall wage effect on the profit includes the direct wage effect and the indirect effect via effort, so that $\frac{d \pi}{d w}=-(1-\phi) \cdot L<0$ when $\phi<1$. Using this and $\frac{d g(\bar{e})}{d w}=\frac{\bar{e}^{1 / \gamma} \cdot \phi}{w}$ as well as the total wage elasticity of labor $\eta=-\frac{d L}{d w} \frac{w}{L}=\eta_{w}(1-\phi)+\phi=\frac{\gamma+(1-\gamma) \eta_{w}}{1-\gamma+\gamma \eta_{w}}$ the first-order condition (10) can be solved to

$$
w=\frac{\eta b+\bar{e}^{1 / \gamma}(\eta \gamma-\phi)}{\eta-1+\tau(1-\phi)}
$$

From equation (11) one can see that profit sharing will affect the wage in different ways. The first working channel is the direct effect, which one can see in the denominator of (11), while the second is an indirect effect via the total wage elasticity and via effort, respectively via the wage elasticity of effort. Starting with the direct effect, which is described in the denominator of (11), we see that this one can be distinguished into two working channels. The first part of the term $\tau-\tau \phi$ describes the substitution effect. This effect will decrease the base wage, which means that a former part of the base wage is substituted by profit income. Since wage changes also affect effort provision, the second part of the term describes a feedback effect via the elasticity channel. Since a higher wage will decrease profit and therefore profit income, so that it increases the resulting utility loss for the union respectively their member. Due to this increasing effect on the union's marginal costs, higher profit sharing will induce a less aggressive wage setting.

The indirect second working channel is affected by the effect on the labor demand elasticity, effort and wage elasticity of effort. We know that higher profit sharing increase effort and thus productivity. Intuitively, the higher productivity will be compensated by a higher wage level, which one can also see from equation (11). Another indirect impact results from the effect on the wage elasticity of the labor demand. As pointed out in Appendix A, higher profit sharing makes the labor 
demand less elastic, i.e. $\frac{d \eta}{d \tau}<0$, which affects the wage positively. For this result an intuitive explanation can be found. Since higher profit sharing increases effort and induces a higher labor demand (see (3a)). An enhanced labor decreases the utility loss of the union concerning a higher wage, which results in a more aggressive union and a higher wage level. While these effects raise the wage, the effect via the wage elasticity of effort is ambiguous. Using equation (8) and the result $\frac{d \eta_{w}}{d \tau}<0$ we find that $\frac{d \phi}{d \tau}<0$. As one can see from (11) higher profit sharing will have a wage increasing effect (numerator) but also a wage decreasing effect (denominator). Due to this opposed effects we cannot identify the impact of profit sharing on bargained base wage.

We now turn to a detailed mathematically analysis between profit sharing and wage formation originally in the case when the wage elasticity of effort is smaller than one, where the different working channels are demonstrated explicitly. By using $\bar{e}=\left(\frac{\tau \cdot w}{L}\right)^{\gamma}, \eta=\frac{\gamma+(1-\gamma) \eta_{w}}{1-\gamma+\gamma \eta_{w}}$ and $\phi=\frac{\gamma+\gamma \eta_{w}}{1-\gamma+\gamma \eta_{w}}$ we can rewrite equation (11) as follows

$$
w=\frac{\gamma+(1-\gamma) \eta_{w}}{\left(\eta_{w}-1\right)\left(1-2 \gamma+\frac{\tau \gamma^{2}}{L}\right)+\tau \cdot\left(1-2 \gamma+\frac{\gamma}{L}\right)} b=A(c, w, \tau) b
$$

It should be emphasized that the wage is an implicit form as both the numerator and denominator in the mark-up factor, $A(c, w, \tau)$, depend on wage $w$ in a non-linear way via labor demand and direct wage elasticity of labor demand.

The implicit differentiation of (11') with respect to profit sharing gives $\frac{d w}{d \tau}=\frac{A_{\tau} b}{1-A_{w} b}$ and by substituting $b=w / A$ we can characterize this effect on wage formation as

$$
\frac{d w}{d \tau}=\frac{\frac{A_{\tau} w}{A}}{1-\frac{A_{w} w}{A}},
$$


where $1-\frac{A_{w} w}{A}>0$ under the assumption $\tau\left[1-\gamma\left(1-\frac{1}{L}\right)\right] \leq 1$ (see Appendix B).

In terms of profit sharing in Appendix B we point out that there are two effects which influence the term $\frac{A_{\tau} w}{A}$. While the first impact is positive under the assumption $\tau \leq\left[1-\gamma\left(1-\frac{1}{L}\right)\right]^{-1}$, the second impact will be negative if outsourcing is not too high relative to effective domestic labor demand, i.e. as $\frac{M}{\bar{e} L}<\frac{1}{\gamma}$. Therefore, under these assumptions effect of profit sharing on wage formation is a priori ambiguous, which means that $\frac{A_{\tau} w}{A}=$ ? if $\phi<1$.

We can summarize our finding as follows. ${ }^{14}$

Proposition 2: In the presence of flexible outsourcing when the base wage elasticity of effort is smaller than one higher profit sharing will have an ambiguous effect on wage formation when $\tau \leq\left[1-\gamma\left(1-\frac{1}{L}\right)\right]^{-1}$ and when outsourcing is not too high relative to effective labor, i.e. $\frac{M}{\bar{e} L}<\frac{1}{\gamma}$.

However, we can also analyze the impact of profit sharing on wage for the special case $\gamma=1 / 2$ where the wage elasticity of effort is one, i.e. $\phi=1$. In this case, the effect of profit sharing can be expressed as

$$
\left.\frac{d w}{d \tau}\right|_{\phi=1}=\frac{\frac{w}{\tau}\left(\left.\frac{d L}{d \tau} \frac{\tau}{L}\right|_{\phi=1}-1\right)}{1-\left.\frac{d L}{d \tau} \frac{\tau}{L}\right|_{\phi=1}}=\frac{1}{2} \frac{w}{\tau}\left(\left.\frac{d L}{d \tau} \frac{\tau}{L}\right|_{\phi=1}-1\right)<0
$$

14 One can also show in this model that lower cost of outsourcing decreases wage formation under the assumption $\tau \leq\left[1-\gamma\left(1-\frac{1}{L}\right)\right]^{-1}$. Lower outsourcing cost means for given wage level a higher outsourcing demand and a more elastic low skilled labor demand. Thus the opportunity for the labor union to set higher wages falls. This lies in conformity with empirics concerning evidence from various countries, e.g. Feenstra and Hanson (1999), Hijzen et al. (2005), Hsieh and Woo (2005), Egger and Egger (2006), Geishecker and Görg (2008) and Munch and Skaksen (2009). 
where $\left.\frac{d L}{d \tau} \frac{\tau}{L}\right|_{\phi=1}=\frac{\alpha+(2-\alpha) \frac{M}{\bar{e} L}}{2-\alpha+\frac{M}{\bar{e} L}}<1$ as $\frac{M}{\bar{e} L}<2$ and

We can now summarize this finding as.

Corollary 1: In the presence of flexible outsourcing when the base wage elasticity of effort is one higher profit sharing will have a negative effect on wage formation when outsourcing is sufficiently low relative to effective domestic labor.

Knowing the wage effects, we can demonstrate the effects of committed profit sharing on outsourcing and employment. We can write the working channel of committed profit sharing on the amount of flexible outsourcing as $\frac{d M}{d \tau}=\frac{\partial M}{\partial \bar{e}} \cdot \frac{d \bar{e}}{d \tau}+\frac{\partial M}{\partial w} \cdot \frac{d w}{d \tau}$ where $\frac{d \bar{e}}{d \tau}>0, \frac{\partial M}{\partial \bar{e}}<0$ and $\frac{\partial M}{\partial w}>0$. Using the former results, we in the general case with, i.e. $\phi<1$

$$
\frac{d M}{d \tau}=\underbrace{\frac{\partial M}{\partial \bar{e}} \cdot \frac{d \bar{e}}{d \tau}}_{-}+\underbrace{\frac{\partial M}{\partial w}}_{+} \cdot \underbrace{\frac{d w}{d \tau}}_{?}=?
$$

If the wage elasticity of effort is one and $\left.\frac{d L}{d \tau} \frac{\tau}{L}\right|_{\phi=1}<1$ is fulfilled, we know from equation (13) that $\left.\frac{d w}{d \tau}\right|_{\phi=1}<0$. In that case, we therefore find for the impact of profit sharing on outsourcing

$$
\left.\frac{d M}{d \tau}\right|_{\phi=1}=\underbrace{\frac{\partial M}{\partial \bar{e}} \cdot \frac{d \bar{e}}{d \tau}}_{-}+\underbrace{\frac{\partial M}{\partial w}}_{+} \cdot \underbrace{\left.\frac{d w}{d \tau}\right|_{\phi=1}}_{-}<0 .
$$

Based on the outsourcing effect of profit sharing, one can also analyze the effect of committed profit sharing on employment. The employment impact can be formalized as $\frac{d L}{d \tau}=\frac{\partial L}{\partial \bar{e}} \cdot \frac{d \bar{e}}{d \tau}+\frac{\partial L}{\partial w} \cdot \frac{d w}{d \tau}$ where $\frac{d \bar{e}}{d \tau}>0, \frac{\partial M}{\partial \bar{e}}<0$ and $\frac{\partial L}{\partial w}<0$. Using the former results, we have in the general case 


$$
\frac{d L}{d \tau}=\underbrace{\frac{\partial L}{\partial \bar{e}} \cdot \frac{d \bar{e}}{d \tau}}_{+}+\underbrace{\frac{\partial L}{\partial w}}_{-} \cdot \underbrace{\frac{d w}{d \tau}}_{?}=?
$$

For the special case when the wage elasticity of effort is one and outsourcing is sufficiently low, i.e. $\frac{M}{\bar{e} L}<\frac{1}{2}$ and therefore $\left.\frac{d L}{d \tau} \frac{\tau}{L}\right|_{\phi=1}<1$, by using our former results, we have

$$
\left.\frac{d L}{d \tau}\right|_{\phi=1}=\underbrace{\frac{\partial L}{\partial \bar{e}} \cdot \frac{d \bar{e}}{d \tau}}_{+}+\underbrace{\frac{\partial L}{\partial w}}_{-} \cdot \underbrace{\left.\frac{d w}{d \tau}\right|_{\phi=1}}_{-}>0 .
$$

We can now summarize these findings as.

Proposition 3: The effect of profit sharing on flexible outsourcing and domestic employment has

(a) an ambiguous effect and when base wage elasticity of effort smaller than one $(\phi<1)$, and profit sharing elasticity of labor demand is smaller than one, while

(b) a negative effect on flexible outsourcing and a positive effect on employment when base wage elasticity of effort is one $(\phi=1)$, and profit sharing elasticity of labor demand is smaller than one.

\section{III.2. Optimal Committed Profit Sharing}

Concerning the timing structure presented in Section II the representative firm has been assumed to commit to profit sharing to maximize profit subject to domestic labor demand (3a), outsourcing (3b), effort determination (7) and wage formation (11') so that we have to analyze the following specification

$$
\begin{aligned}
\underbrace{\operatorname{Max}}_{\tau} \bar{\pi}= & (1-\tau)\left[\frac{1}{\alpha}(\bar{e} L+M)^{\alpha}-w L-\frac{1}{2} c M^{2}\right] \text { s.t. } \\
L & =w^{-\frac{1}{1-\alpha}} \bar{e}^{\frac{\alpha}{1-\alpha}}-\frac{M}{\bar{e}}=w^{-\frac{1}{1-\alpha}} \bar{e}^{\frac{\alpha}{1-\alpha}}-\frac{w}{c \bar{e}^{-2}}, \\
e & =\bar{e}=\left(\frac{\tau \cdot w}{L}\right)^{\gamma},
\end{aligned}
$$




$$
w=\frac{\gamma+(1-\gamma) \eta_{w}}{\left(\eta_{w}-1\right)\left(1-2 \gamma+\frac{\tau \gamma^{2}}{L}\right)+\tau\left(1-2 \gamma+\frac{\gamma}{L}\right)} b
$$

From (18) we get the first-order condition $-\pi^{*}+(1-\tau) \pi_{\tau}^{*}=0$, where the indirect profit function is $\pi^{*}=\frac{1-\alpha}{\alpha}\left[w^{-\frac{\alpha}{1-\alpha}} \frac{\alpha}{e^{1-\alpha}}\right]+\frac{1}{2} \frac{w^{2}}{c e^{2}}$. Concerning the derivate of the indirect profit in terms of profit sharing we have (see Appendix C) $\pi_{\tau}^{*}=\frac{w L}{\tau}\left(-\frac{d w}{d \tau} \frac{\tau}{w}+\frac{d \bar{e}}{d \tau} \frac{\tau}{\bar{e}}\right)=\frac{w L}{\tau}\left(\mu-\frac{d w}{d \tau} \frac{\tau}{w}\right)$ so that the optimal committed profit sharing in the presence of flexible outsourcing is

$$
\tau=\frac{\frac{\alpha}{1-\alpha}\left(\mu-\frac{d w}{d \tau} \frac{\tau}{w}\right)}{\left[1+\frac{\alpha}{1-\alpha}\left(\phi^{\tau}-\frac{d w}{d \tau} \frac{\tau}{w}\right)+\frac{2-\alpha}{2(1-\alpha)} \frac{M}{\bar{e} L}\right]},
$$

where is $\mu$ is the effort elasticity in terms of profit sharing and $\frac{d w}{d \tau} \frac{\tau}{w}=$ ?. This is an implicit form for profit sharing because both employee effort and labor demand depend on profit sharing in a non-linear way and both numerator and denominator depend on outsourcing.

Using the first-order condition $(1-\tau) \cdot \pi_{\tau}^{*}=\pi^{*}$ and $\pi^{*}>0$ one can answer our third research question and show that the firm will implement a profit sharing scheme. This results, since the right-side is positive and therefore to fulfill this equation also the left side has to be positive. If $\pi_{\tau}^{*}>0$ this will be the case for $0<\tau<1$. For the case $\pi_{\tau}^{*}<0$ the profit share has to be higher than one, i.e. $\tau>1$. Thus, one can conclude that the optimal profit share is at least positive.

Proposition 4: For individual effort provision, the firm will optimally implement a profit sharing scheme.

Koskela and König (2009) have analyzed committed profit sharing in the case of labour union determination of wage and effort and by showing a constant effort 
level will result so that in this case firm's optimal choice of profit sharing is zero. The difference between both approaches is that now the firm will induce higher productivity with the implementation of profit sharing, while this does not happen in Koskela and König (2009). Therefore the firm will not lose due to profit sharing. This result shows that the time structure with individual effort determination will generate an alternative compensation scheme with profit sharing, while in the presence of union effort determination such a scheme would optimally not be implemented.

\section{Conclusions}

Associated outsourcing and committed profit sharing under labor market imperfection with flexible outsourcing we have analyzed the following questions: First, how does the implementation of profit sharing affect effort and thus

productivity? Second, how does profit sharing influence the bargained wage and thus outsourcing demand? Third, will the firm implement a profit sharing scheme, if workers decide individually about effort provision?

We have found the intuitive result that profit sharing and the wage level have an individual effort-augmenting effect and therefore increase productivity. This results from the fact, that higher profit sharing increases the income, which set incentive to increase the working effort to realize more profit and therefore to increase the income. Concerning our second question, we demonstrate that the wage effect of profit sharing is ambiguous. On the hand, there is a wage decreasing substitution effect, but on the other hand, there is a wage increasing effect via labor demand elasticity. Therefore, the outsourcing and employment effect is also ambiguous. To your third question, we find that there will be a firm's optimally committed profit sharing under individual effort determination. This result shows that to the individual effort provision and therefore the productivity effect is decisive to implement an alternative compensation scheme where the income is uncoupled on the wage.

An important new research question would be to analyze the impacts of both product market and labor market imperfections on profit sharing, wage, outsourcing 
and unemployment. In the absence of profit sharing Lommerud et al. (2006) have shown how international mergers might restrain the market power of unions in oligopoly markets giving socially excessive incentives for international mergers, unless products are close substitutes. An additional aspect might be the analysis of the effects on outsourcing, if profit sharing is implemented in the wage bargaining, where simultaneous the profit share and wage will be determined.

\section{Appendix A: Calculations of the total and direct own wage elasticities in terms of wage, outsourcing cost and profit sharing}

In our framework, the base wage $w$ affects labor demand in two different ways and thus we can separate the elasticity in an direct labor demand effect and an indirect labor demand effect via effort as follows: $\eta=-\frac{\partial L}{\partial w} \frac{w}{L}-\frac{\partial L}{\partial \bar{e}} \frac{\bar{e}}{L} \cdot \frac{w}{\bar{e}} \frac{d \bar{e}}{d w}$. These effects can be expressed as $-\frac{\partial L}{\partial w} \frac{w}{L}=\eta_{w}, \frac{\partial L}{\partial \bar{e}} \frac{\bar{e}}{L}=\eta_{w}-1$ and $\frac{d \bar{e}}{d w} \frac{w}{\bar{e}}=\phi$, so that we can rewrite the total wage elasticity by using the wage elasticity of effort as follows

$$
\eta=-\frac{d L}{d w} \frac{w}{L}=\eta_{w}(1-\phi)+\phi=\frac{\gamma+(1-\gamma) \eta_{w}}{1-\gamma+\gamma \eta_{w}} .
$$

which is a negative function of wage elasticity of effort $\phi=\frac{d \bar{e}}{d w} \frac{w}{\bar{e}}$. The special assumption $\gamma=1 / 2$ gives $\eta=1$. The total wage elasticity can be presented in terms of direct wage elasticity as

$$
\frac{\partial \eta}{\partial \eta_{w}}=\frac{1-2 \gamma}{\left(1-\gamma+\gamma \eta_{w}\right)^{2}}>0 \text { as } \gamma<\frac{1}{2},
$$

so that there is the positive relationship between the total wage elasticity and the direct own wage elasticity in the case $\gamma<1 / 2$.

The effect of wage rate on the direct own wage elasticity (using equation (4a)) can be expressed as

$$
\frac{d \eta_{w}}{d w}=\frac{1}{1-\alpha}\left(\frac{\bar{e} L \frac{d M}{d w}-M \frac{d(\bar{e} L)}{d w}}{(\bar{e} L)^{2}}\right)=\frac{M}{(1-\alpha) \bar{e} L w}(1-\phi)\left(1+\eta_{w}\right)>0 \text { as } \phi<1
$$


Under the assumption that the wage elasticity of effort is smaller than one, higher wage will increase the direct own wage elasticity so that in this case it will also increase the total wage elasticity of labor demand according to equation (A2).

Finally, the effect of profit sharing on the direct own wage elasticity (using equation (4a)) can be expressed as

$$
\frac{d \eta_{w}}{d \tau}=\frac{1}{1-\alpha}\left(\frac{\bar{e} L \frac{d M}{d \tau}-M \frac{d(\bar{e} L)}{d \tau}}{(\bar{e} L)^{2}}\right)=-\frac{M}{(1-\alpha) \bar{e} L \tau} \frac{2-\alpha}{1-\alpha}\left(\mu+\frac{M}{\bar{e} L}\right)<0
$$

According to this higher profit sharing will decrease the direct own wage elasticity. ${ }^{15}$ Therefore, in terms of total wage elasticity of labor demand when wage elasticity of effort being smaller than one, $\phi<1$, higher wage and also lower outsourcing cost will increase the total wage elasticity of labor demand $\frac{d \eta}{d w}=\frac{\partial \eta}{\partial \eta_{w}} \cdot \frac{d \eta_{w}}{d w}>0$, while higher profit sharing will decrease the total wage elasticity of labor demand $\frac{d \eta}{d \tau}=\frac{\partial \eta}{\partial \eta_{w}} \cdot \frac{d \eta_{w}}{d \tau}<0$, .QED.

\section{Appendix B: Derivations of the relationships between profit sharing and wage formation}

Based on straightforward calculations we find that the effect of wage on the markup can be expressed by using $A=\left(\gamma+(1-\gamma) \eta_{w}\right) / X$ (equation (11')), where

$$
\begin{gathered}
X=\left(\eta_{w}-1\right)\left(1-2 \gamma+\frac{\tau \gamma^{2}}{L}\right)+\tau\left(1-2 \gamma+\frac{\gamma}{L}\right), \\
A_{w}=X^{-2}\left[X(1-\gamma) \frac{d \eta_{w}}{d w}-\left(\gamma+(1-\gamma) \eta_{w}\right) \frac{d X}{d w}\right] \text { so that } \\
\frac{A_{w} w}{A}=\frac{w\left[X(1-\gamma) \frac{d \eta_{w}}{d w}-\left(\gamma+(1-\gamma) \eta_{w}\right) \frac{d X}{d w}\right]}{X\left(\gamma+(1-\gamma) \eta_{w}\right)}
\end{gathered}
$$

15 One can also show that lower outsourcing cost will increase the total wage elasticity of labor demand, i.e. $\frac{d \eta}{d c}<0$, which lies in conformity with empirics, see e.g. Slaughter (2001). 
where $\quad \frac{d \eta_{w}}{d w} w=\frac{M}{(1-\alpha) \bar{e} L}(1-\phi)\left(1+\eta_{w}\right) \geq 0 \quad$ as $\quad \phi \leq 1 \quad$ and $\frac{d X}{d w} w=\left(1-2 \gamma+\frac{\tau \gamma^{2}}{L}\right) \frac{d \eta_{w}}{d w} w+\left(\eta_{w}-1\right) \frac{\tau \gamma^{2}}{L}\left(-\frac{d L}{d w} \frac{w}{L}\right)+\frac{\tau \gamma}{L}\left(-\frac{d L}{d w} \frac{w}{L}\right)$, which can be rewritten as

$\frac{d X}{d w} w=\left(1-2 \gamma+\frac{\tau \gamma^{2}}{L}\right) \frac{d \eta_{w}}{d w} w+\left[\frac{\gamma+(1-\gamma) \eta_{w}}{1-\gamma+\gamma \eta_{w}}\right]\left(\left(\eta_{w}-1\right) \frac{\tau \gamma^{2}}{L}+\frac{\tau \gamma}{L}\right)>0$ as $\phi \leq 1$

Using (B2) and $Y=X\left(\gamma+(1-\gamma) \eta_{w}\right)$ we can express (B1) as

$$
\frac{A_{w} w}{A}=Y^{-1}\left(\frac{d \eta_{w}}{d w} w\left[(1-2 \gamma)\left[\tau\left(1-\gamma\left(1-\frac{1}{L}\right)\right)-1\right]\right]-\frac{\left[\left(\gamma+(1-\gamma) \eta_{w}\right)\right]^{2}}{1-\gamma+\gamma \eta_{w}}\left(\left(\eta_{w}-1\right) \gamma+1\right) \frac{\tau \gamma}{L}\right)<0
$$

since $\frac{d \eta_{w}}{d w} \geq 0$ and as the wage elasticity of effort does not exceed one, i.e. $\phi \leq 1$ and $\tau\left[1-\gamma\left(1-\frac{1}{L}\right)\right] \leq 1$. In this case we have $1-\frac{A_{w} w}{A}>0$.

Finally, the effect of profit sharing on the mark-up can be expressed by using $A_{\tau}=X^{-2}\left[X(1-\gamma) \frac{d \eta_{w}}{d \tau}-\left(\gamma+(1-\gamma) \eta_{w}\right) \frac{d X}{d \tau}\right]$ so that we have

$$
\frac{A_{\tau} w}{A}=\frac{w\left[X(1-\gamma) \frac{d \eta_{w}}{d \tau}-\left(\gamma+(1-\gamma) \eta_{w}\right) \frac{d X}{d \tau}\right]}{X\left(\gamma+(1-\gamma) \eta_{w}\right)}
$$

where $\quad \frac{d \eta_{w}}{d \tau}=-\frac{M}{(1-\alpha) \bar{e} L \tau} \frac{2-\alpha}{1-\alpha}\left(\mu+\frac{M}{\bar{e} L}\right)<0$ and $\frac{d X}{d \tau}=\left(1-2 \gamma+\frac{\tau \gamma^{2}}{L}\right) \frac{d \eta_{w}}{d \tau}-\left(\left(\eta_{w}-1\right) \gamma+1\right) \frac{\gamma}{L}\left(\frac{d L}{d \tau} \frac{\tau}{L}\right)+1-2 \gamma+\left(\left(\eta_{w}-1\right) \gamma+1\right) \frac{\gamma}{L}$, where $\frac{d L}{d \tau} \frac{\tau}{L}=\left[\frac{\alpha}{1-\alpha}+\frac{2-\alpha}{1-\alpha} \frac{M}{\bar{e} L}\right] \cdot \mu, \quad \mu=\frac{d \bar{e}}{d \tau} \frac{\tau}{\bar{e}}=\frac{\gamma}{1+\gamma\left(\eta_{w}-1\right)}>0$, so that this profit sharing total labor demand elasticity can be written as $\frac{d L}{d \tau} \frac{\tau}{L}=\left[\frac{\gamma\left(\alpha+(2-\alpha) \frac{M}{\bar{e} L}\right)}{(1-\alpha)\left(\left(\eta_{w}-1\right) \gamma+1\right)}\right]>0$. Using these (B4) can be written as 


$$
\frac{A_{\tau} w}{A}=Y^{-1} w\left(\begin{array}{l}
\frac{d \eta_{w}}{d \tau}\left[(1-2 \gamma)\left[\tau\left(1-\gamma\left(1-\frac{1}{L}\right)\right)-1\right]\right] \\
+\left(\gamma+(1-\gamma) \eta_{w}\right)\left[\left(\left(\eta_{w}-1\right) \gamma+1\right) \frac{\tau \gamma}{L}\left(\frac{d L}{d \tau} \frac{\tau}{L}-1\right)-(1-2 \gamma)\right]
\end{array}\right)
$$

where the first term is positive under the assumption $\tau\left[1-\gamma\left(1-\frac{1}{L}\right)\right]<1$ and under the assumption that $\gamma<1 / 2$. Concerning the second term and using $\eta_{w}=\frac{1}{1-\alpha}\left(1+\frac{M}{\bar{e} L}\right)$, the elasticity of labor demand in terms of profit sharing is $\frac{d L}{d \tau} \frac{\tau}{L}=\left[\frac{\gamma\left(\alpha+(2-\alpha) \frac{M}{\bar{e} L}\right)}{(1-\alpha)\left(1-\gamma+\gamma \eta_{w}\right)}\right]<1$ as $\frac{M}{\bar{e} L}<\frac{1}{\gamma}$ so that under this assumption the second term is negative so that in these assumptions the effect of profit sharing on wage formation is a priori ambiguous, $\frac{d w}{d \tau}=$ ? QED.

\section{Appendix C: Effect of profit sharing on indirect profit}

Differentiating the indirect profit $\pi^{*}=\frac{1-\alpha}{\alpha}\left[w^{-\frac{\alpha}{1-\alpha}} \bar{e}^{\frac{\alpha}{1-\alpha}}\right]+\frac{1}{2} \frac{w^{2}}{c e^{2}}$ in terms of $\tau$ gives $\pi_{\tau}^{*}=\left[-w^{-\frac{1}{1-\alpha}} \frac{\alpha}{e^{1-\alpha}} \frac{d w}{d \tau}+w^{-\frac{\alpha}{1-\alpha}} \frac{\alpha}{\bar{e}^{1-\alpha}} \frac{d \bar{e}}{d \tau} \frac{1}{\bar{e}}\right]+\frac{w^{2}}{c \bar{e}^{2}}\left[\frac{d w}{d \tau} \frac{1}{w}-\frac{d \bar{e}}{d \tau} \frac{1}{\bar{e}}\right]$. Using $\frac{w^{2}}{c \bar{e}^{2}}=\frac{w M}{\bar{e}}$ and $w^{-\frac{1}{1-\alpha}} \frac{\alpha}{e^{1-\alpha}}=L+\frac{M}{\bar{e}}$ this can be expressed as

$$
\pi_{\tau}^{*}=\frac{w}{\tau}\left(L+\frac{M}{\bar{e}}\right)\left(-\frac{d w}{d \tau} \frac{\tau}{w}+\frac{d \bar{e}}{d \tau} \frac{\tau}{\bar{e}}\right)+\frac{w M}{\bar{e} \tau}\left(\frac{d w}{d \tau} \frac{\tau}{w}-\frac{d \bar{e}}{d \tau} \frac{\tau}{\bar{e}}\right)=\frac{w L}{\tau}\left(\mu-\frac{d w}{d \tau} \frac{\tau}{w}\right)
$$

By using (C1) and $\pi^{*}=\frac{1-\alpha}{\alpha}\left[w^{-\frac{\alpha}{1-\alpha}} \frac{\alpha}{\bar{e}^{1-\alpha}}\right]+\frac{1}{2} \frac{w^{2}}{c e^{2}}=\frac{1-\alpha}{\alpha} w L+\frac{w M}{\bar{e}}\left(\frac{1-\alpha}{\alpha}+\frac{1}{2}\right)$ the first-order condition $-\pi^{*}+(1-\tau) \pi_{\tau}^{*}=0$ can be solved to equation (19). QED.

\section{References:}

Akerlof, G. A. and J. L. Yellen (1986) (eds.): Efficiency Wage Models of the Labor Market, Cambridge University Press, MA. 
Amiti, M. and S.-J. Wei (2005): Fear of Service Outsourcing: Is It Justified?, Economic Policy 20, 307-347.

Booth, A. J. and J. Frank (1999): Earnings, Productivity, and Performed-Related Pay, Journal of Labor Economics 17, 447-463.

Cable, J. R. and F. R. FitzRoy (1980): Cooperation and Productivity: Some Evidence from West Germany's Experience, Economic Analysis and Workers Management 14, 163-190.

Cable, J. and N. Wilson (1990): Profit Sharing and Productivity: Some Further Evidence, Economic Journal 100, 550-555.

Cahuc, P. and B. Dormont (1997): Profit Sharing: Does It Increase Productivity and Employment? A Theoretical Model and Empirical Evidence on French Micro Data, Labour Economics 4, 293-319.

Cahuc, P. and A. Zylberberg (2004): Labor Economics, MIT Press.

Conyon, M. and R. Freeman (2004): Shared Modes of Compensation and Firm Performance: U.K. Evidence, in: Card, D. R. Blundell and R. B. Freeman (eds.): Seeking a Premier Economy: the Economic Effects of British Economy Reforms 1980-2000, 109-146.

Egger, H. and P. Egger (2006): International Outsourcing and the Productivity of Low-Skilled Labor in the EU, Economic Inquiry 44, 98-108.

Estrin, S., Perotin, V., Robinson, A. and N. Wilson (1997): Profit-Sharing in OECD Countries: a Review and Some Evidence, Business Strategy Review 8, 27-32.

Geishecker, I. and H. Görg (2008): Winners and Losers: A Micro-Level Analysis of International Outsourcing and Wages, Canadian Journal of Economics 41, 243-270.

Görg, H. and A. Hanley (2005): Labour Demand Effects of International Outsourcing: Evidence from Plant-Level Data, International Review of Economics and Finance 14, 365-376.

Feenstra, R. C. and G. H. Hanson (1999): The Impact of Outsourcing and HighTechnology Capital on Wages: Estimates for the United States 1979-1990, Quarterly Journal of Economics 114, 907-940. 
Fung, K. C. (1989): Profit Sharing and European Unemployment, European Economic Review 33, 1787-1798.

Hijzen, A., Görg, H. and R. C. Hine (2005): International Outsourcing and the Skill Structure of Labour Demand in the United Kingdom, Economic Journal 115, 860-878.

Holmlund, B. (1990): Profit Sharing, Wage Bargaining, and Unemployment, Economic Inquiry 28, 257-268.

Holmstrom, B. (1982): Moral Hazard in Teams, Bell Journal of Economics 13, 324340.

Holmstrom, B. and P. Milgrom (1990): Regulating Trade among Agents, Journal of Institutional and Theoretical Economics 146, 85-105.

Hsieh, C-T. and K. T. Woo (2005): The Impact of Outsourcing to China on Hong Kong’s Labor Market, American Economic Review 95, 1673-1687.

Jellal, M. and Y. Zenou (2000): A Dynamic Efficiency Wage Model with Learning by Doing, Economics Letters 66, 99-105.

Jensen, M. And W. Meckling (1979): Rights and Production Functions: An Application to Labour-Managed Firms in Co-Determination, Journal of Business 52, 469-506.

Kandel, E. and E. P. Lazear (1992): Peer Pressure and Partnerships, Journal of Political Economy 100, 801-817.

Koskela, E. and J. König (2009): Can Profit Sharing Lower Flexible Outsourcing? A Note, CESifo Working Paper No. 2606.

Koskela, E. and R. Stenbacka (2006): Flexible and Committed Profit Sharing with Wage Bargaining: Implications for Equilibrium Unemployment, Journal of Economics 87, 159-180.

Kraft, K. and M. Ugarkovic (2005): Profit-Sharing: Supplement or Substitute?, Dortmund University, Working Paper.

Kruse, D. L. (1992): Profit Sharing and Productivity: Microeconomic Evidence from the United States, Economic Journal 102, 24-36. 
Kruse, D. L. (1993): Does Profit Sharing Affect Productivity?, NBER Working Paper, No. 4542.

Lin, C. C., J.-J. Chang and C.-C. Lai (2002): Profit Sharing as a Worker Discipline Device, Economic Modelling 19, 815-828.

Lommerud, K. E., O. R. Straume and L. Sorgard (2006): National versus International Mergers in Unionized Oligopoly, Rand Journal of Economics 37, 212-233.

Lynn Hannan, R. (2005): The Combined Effect of Wages and Firm Profit on Employee Effort, The Accounting Review 80, 167-188.

Munch, J. R. and J. R. Skaksen (2009): Specialization, Outsourcing and Wages, Review of World Economics 145, 57-73.

Pendleton, A., E. Poutsma, J. van Ommeren and C. Brester (2001): Employee Share Ownership and Profit Sharing in the European Union, Office for Official Publications of the European Commission, Luxembourg.

Radner, R. (1986): Repeated Partnership Games with Imperfect Monitoring and No Discounting, Review of Economic Studies 53, 43-57.

Slaughter, M. J. (2001): International Trade and Labor-demand Elasticities, Journal of International Economics 64, 27-56.

Stefanova, B. M. (2006): The Political Economy of Outsourcing in the European Union and the East-European Enlargement, Business and Politics 8, article 3.

Varian, H. (1990): Monitoring Agents with Other Agents, Journal of Institutional and Theoretical Economics 146, 153-174.

Wadhwani, S. (1988): Profit Sharing as a Cure for Unemployment, International Journal of Industrial Organization 6, 59-68.

Wadhwani, S. and M. Wall (1990): The Effects of Profit Sharing on Employment, Wages, Stock Returns and Productivity: Evidence from U.K. Micro data, Economic Journal 100, 1-17.

Weitzman, M. L. (1987): Steady State Unemployment under Profit Sharing, Economic Journal 97, 86-105. 